\title{
Evaluation of Occupational Fatalities among Underground Coal Mine Workers through Hierarchical Loglinear Models
}

\author{
Mustafa ONDER ${ }^{1 *}$ and Erhan ADIGUZEL ${ }^{1}$ \\ ${ }^{1}$ Department of Mining Engineering, Eskisehir Osmangazi University, Eskisehir, Turkey
}

Received March 24, 2009 and accepted March 15, 2010

\begin{abstract}
Despite the all precautions, underground coal mining is one of the dangerous industries owing to fatal occupational accidents. Accidents are complicated events to which many factors effect on their formation and preventing them is only possible by the analyses of the accident occurred in past and by straight evaluation of the obtained results. In this study, hierarchical loglinear analysis method was implemented to occupational fatalities occurred in the period of 1980-2004 in the five underground coal mines of Turkish Hardcoal Enterprises which has the most important coal production areas in Turkey. The accident records were evaluated and the main factors affecting the accidents were defined as mine, miners' age, occupation, and accident type. By taking into account the sub factors of the main factors, multi way contingency tables were prepared and thus, the probabilities might effect fatality accidents were investigated. At the end of this study, it was found that the mostly affected job group by the fatality accidents was the production workers and additionally, these workers were mostly exposed to roof collapses and methane explosions. Moreover, important accident risk factors and the occupational job groups which have high probability to be exposed to these risk factors were determined and important information about decreasing the accidents in the underground coal mines were presented.
\end{abstract}

Key words: Accident analysis, Hierarchical loglinear models, Odds ratio, Underground coal mining

\section{Introduction}

The mining industry has a high incidence of injury among all industry divisions, particularly of fatal injures ${ }^{1)}$. Despite the record of progress that has been achieved in reducing mining fatalities and injures, both the number and severity of mining accidents are still unacceptable ${ }^{2)}$. Common causes of fatal injury include rock falls, fires, explosions, mobile equipment accidents, and electrocution ${ }^{3)}$. To identify the potential problem areas, it is necessary to investigate the causes of accidents and their control through quantitative analysis of accident data ${ }^{4)}$. The objective of accident analysis is to prevent accidents in the future. For the accident prevention, it is necessary to identify common factors

*To whom correspondence should be addressed.

E-mail: monder@ogu.edu.tr and characteristics contributing to the fatal and nonfatal accidents, respectively. Strategies for accident prevention should be in reasonable agreement with significant variables of occupational accidents. These results can be used to develop more effective accidental occupational death and injury prevention programs ${ }^{5}$.

Underground coal mining has the highest occupational fatality incidence rate in Turkey ${ }^{6}$ ). The rate of injury due to underground coal mining accidents is the highest with an injury rate of $10.1 \%$ according to the Social Insurance Institution ${ }^{7}$. In this study, fatal occupational accidents occurred in Turkish Hardcoal Enterprises between the years 1980-2004 were examined. The accidents were categorized in terms of mine, miners' age, occupation, and accident type and statistical analysis were performed using SPSS package program. Hierarchical loglinear models were used to determine the degree of interaction between the variables. As a 
result of the study, the most important risk elements of the occupational accidents in all the enterprises have been determined.

\section{Methods}

\section{Loglinear models}

The purpose of loglinear modeling is the analysis of association and interaction patterns. Loglinear models are of use primarily when at least two variables are response variables. A common use is modeling cell counts in contingency tables. Although loglinear models can be used to analyze the relationship between two categorical variables (two-way contingency tables), they are more commonly used to evaluate multiway contingency tables that involve three or more variables. Loglinear models for higher dimensions are more complex than for two-way tables, because of the variety of potential association terms. The variables investigated by loglinear models are all treated as response variables and therefore, loglinear models demonstrate association between variables ${ }^{8,9)}$.

Hierarchical loglinear models express the logarithm of cell probabilities as a sum of effects. The fullest loglinear model includes a constant, the main effects of each variable, and all two and higher order interactions. This model is known as the saturated model because it has as many parameters as there are cells in the table, and thus fits the data perfectly ${ }^{8,10}$. The loglinear model used in this study is constructed from four-way contingency table (Table 1) of mine (W), miners' age (X), occupation (Y), and accident type (Z).

A four-way hxixjxk cross-classification of response variables $\mathrm{W}, \mathrm{X}, \mathrm{Y}$, and $\mathrm{Z}$ has several potential types of independence ${ }^{8)}$. The saturated loglinear model includes both main effects of the variables and their interaction effects $^{4}$. The saturated loglinear model for the fourway contingency table is expressed as follows ${ }^{8}$.

$\log \mu_{h i j k}=\lambda+\lambda_{h}^{W}+\lambda_{i}^{X}+\lambda_{j}^{Y}+\lambda_{k}^{Z}+\lambda_{h i}^{W X}+\lambda_{h j}^{W Y}+\lambda_{h k}^{W Z}$

$$
\begin{aligned}
& +\lambda_{i j}^{X Y}+\lambda_{i k}^{X Z}+\lambda_{j k}^{Y Z}+\lambda_{h i j}^{W X Y}+\lambda_{h i k}^{W X Z}+\lambda_{h j k}^{W Y Z} \\
& +\lambda_{i j k}^{X Y Z}+\lambda_{h i j k}^{W X Y Z}
\end{aligned}
$$

Where,

$\lambda$ : Constant

$\lambda_{h}^{W}, \lambda_{i}^{X}, \lambda_{j}^{Y}, \lambda_{k}^{Z}:$ Main effects,

$\lambda_{h i}^{W X}, \lambda_{h j}^{W Y}, \lambda_{h k}^{W Z}, \lambda_{i j}^{X Y}, \lambda_{i k}^{X Z}, \lambda_{j k}^{Y Z}: 2$ nd order interactions,

$\lambda_{\text {hij }}^{W X Y}, \lambda_{\text {hik }}^{W X Z}, \lambda_{\text {hjk }}^{W Y Z}, \lambda_{i j k}^{X Y Z}$ : 3rd order interactions,

$\lambda_{\text {hijk }}^{W X Y Z}: 4$ th order interactions.

\section{Collecting of data for the loglinear model}

Accident analyses are used to identify common factors contributing to occupational accidents and to give

\begin{tabular}{|c|c|c|c|}
\hline Mine & Age & Occupation & Accident \\
\hline \multirow[t]{17}{*}{ Mine1 } & Age1 & Occupation1 & Accident 1 \\
\hline & & & Accident 2 \\
\hline & & & Accident 3 \\
\hline & & & Accident 4 \\
\hline & & Occupation2 & Accident 1 \\
\hline & & & Accident 2 \\
\hline & & & Accident 3 \\
\hline & & & Accident 4 \\
\hline & & Occupation3 & Accident 1 \\
\hline & & & Accident 2 \\
\hline & & & Accident 3 \\
\hline & & & Accident 4 \\
\hline & & Occupation4 & Accident 1 \\
\hline & & & Accident 2 \\
\hline & & & Accident 3 \\
\hline & & & Accident 4 \\
\hline & Age2 & - & - \\
\hline- & - & - & - \\
\hline- & - & - & - \\
\hline \multirow[t]{2}{*}{ Mine5 } & Age1 & Occupation 1 & Accident 1 \\
\hline & - & - & - \\
\hline
\end{tabular}

Table 1. Cross-classification table of the variables

recommendations for accident prevention ${ }^{5)}$. The studies conducted on the occurrence of injures in underground coal mines have identified a number of variables affecting mine accidents. Based on the published literature ${ }^{1,4,11-14)}$ and the accident records, the variables chosen in this study were divided into the four main groups such as mine, miners' age, occupation, and accident type.

Accident data were collected from five underground coal mines from 1980 to 2004. The mines are located in the northwestern Turkey on the Black Sea coast and from mining operations point of view; these are the most important production areas in Turkey. There are five coal mines in the basin, namely, Amasra, Armutcuk, Karadon, Kozlu and Uzulmez. It is predicted that the coal reserves in coal basins are about 1.1 billion tons of coal and their area extent is $13,000 \mathrm{~km}^{2}$. The proven reserves include the seams which are present to a depth of $1,200 \mathrm{~m}$, thicknesses varying between 1 and $10 \mathrm{~m}$. The total coal seam thickness is about $40 \mathrm{~m}^{15)}$. The currently applied methods in the mines are longwall caving and wholly manual. The main ventilation methods are the exhausting systems. The number of persons employed in the mines is shown in Fig. 1.

Deaths due to underground coal mining accidents have been recorded officially and a total of 830 occupational fatalities were reported between the years of 1980-2004. All accidents, including occupational ones, 


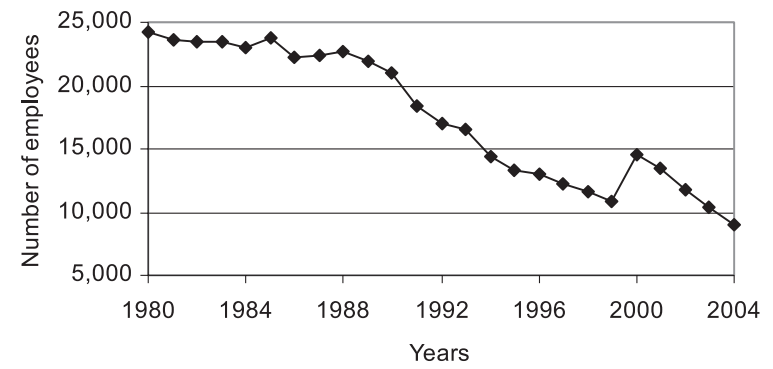

Fig. 1. The total numbers of employees between 1980-2004.

(a)

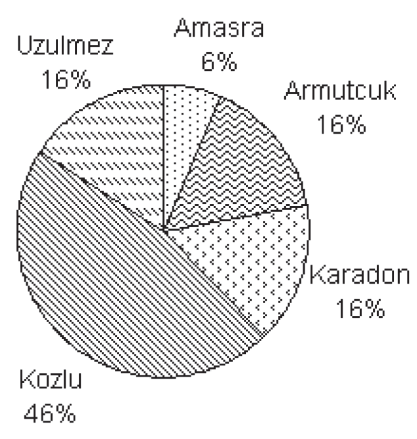

(b)

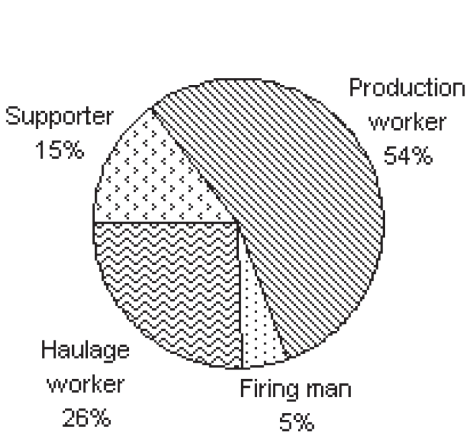

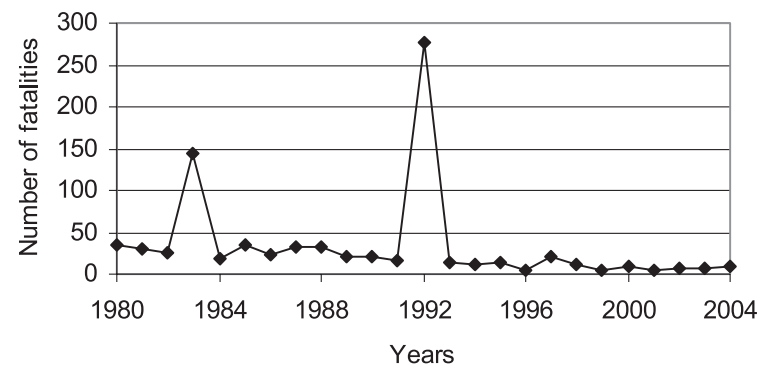

Fig. 2. Number of fatalities in the Turkish Hardcoal Enterprises.

(c)

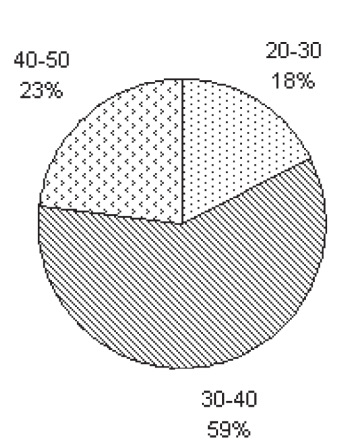

(d)

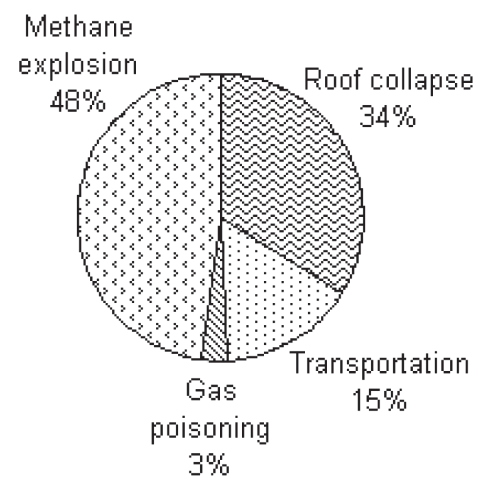

Fig. 3. Percentage distributions of injured persons by mine, occupation, age, and type of accident.

are reported to the legal authorities in order to determine the cause and manner of death ${ }^{6}$. Figure 2 shows the number of fatal injures in the Turkish Hardcoal Enterprises.

In this study, the occupational fatalities were evaluated with respect to mine, age, occupation, and accident type. The mine variable (MINE) has five categories, namely, Amasra, Armutcuk, Karadon, Kozlu and Uzulmez. The age variable (AGE) was categorized into three groups: 20-30 yr, 30-40 yr, and 40-50 yr. The occupation variable (OCCUPATION) has four categories. These are firing man, haulage worker, supporter and production workers. The common responsibilities of these occupational job groups can be given as drilling and blasting for firing man; loading and removing coal from mines for haulage workers; advances, arrangement and maintenances of the support units for supporter; coal excavations for production workers. Causes of accidents leading to fatalities (ACCIDENT) were categorized into four main groups such as roof collapse, transportation, gas poisoning, and methane gas explosions. The percentage distribution of injured persons with respect to the mine (a), occupation (b), age (c), and type of accident (d) are shown in Fig. 3.

As shown in Fig. 3(a), the largest proportion of fatal accidents occurred in Kozlu (46\%). Figure 3(b) indi- cates that the production workers were more likely to be injured than the other workers. The other workers can be put in order as haulage workers (26\%), supporter $(15 \%)$, and firing man $(5 \%)$. The largest proportion of death $(59 \%)$ took place in the age groups of 30-40 yr (Fig. 3(c)). The $23 \%$ of deaths occurred in the age groups of 40-50 yr, followed by 20-30 yr (18\%). In the percentage distribution of fatal injuries as shown in Fig. 3(d), methane explosions (48\%) represents the most common type of fatal accident, followed by roof collapse $(34 \%)$, transportation $(15 \%)$ and gas poisoning $(3 \%)$.

The data collected from five underground coal mines were evaluated with hierarchical loglinear method for detailed investigation of effective factors on fatality accidents and obtained results are given as follows.

\section{Results and Discussions}

Loglinear analysis is a multivariate extension of $\chi^{2}$ used to detect the varying associations and interactions between the variables and provide a systematic approach to the analysis of complex multidimensional tables. The hierarchical loglinear analyses were used in this study and the analyses were carried out by using SPSS. A loglinear analysis was applied to the frequency data 
Table 2. Tests of main effects and higher-order interactions

\begin{tabular}{clrrc}
\hline Degree of Interactions & \multicolumn{1}{c}{ Interactions } & DF & \multicolumn{1}{c}{$\chi^{2}$} & Probability (p) \\
\hline \multirow{4}{*}{ Main effects } & OCCUPATION & 3 & 661,282 & 0.0000 \\
& ACCIDENT & 3 & 656,930 & 0.0000 \\
& AGE & 2 & 574,160 & 0.0000 \\
& MINE & 4 & 512,455 & 0.0000 \\
\hline & MINE*ACCIDENT & 12 & 426,552 & 0.0000 \\
& OCCUPATION*ACCIDENT & 9 & 151,559 & 0.0000 \\
& MINE*AGE & 8 & 33,538 & 0.0040 \\
& AGE*OCCUPATION & 6 & 26,845 & 0.0081 \\
& MINE*OCCUPATION & 12 & 21,578 & 0.3638 \\
& AGE*ACCIDENT & 6 & 13,501 & 0.3337 \\
\hline \multirow{2}{*}{3} & MINE*OCCUPATION*ACCIDENT & 36 & 51,840 & 0.9939 \\
& MINE*AGE*OCCUPATION & 24 & 49,155 & 0.8401 \\
& MINE*AGE*ACCIDENT & 24 & 29,197 & 0.9997 \\
& AGE*OCCUPATION*ACCIDENT & 18 & 22,332 & 0.9994 \\
\hline & MINE*AGE*OCCUPATION*ACCIDENT & 72 & 9,553 & 1.0000 \\
\hline
\end{tabular}

Table 3. The results of fourth-order interaction terms for the loglinear model

\begin{tabular}{lccc}
\hline \multicolumn{1}{c}{ Effect name } & b & OR & CI \\
\hline KOZLU*40-50*FIRING MAN*ROOF COLLAPSE & 0.82 & 2.27 & $0.61-8.43$ \\
KOZLU*20-30*PRODUCTION WORKER*METHANE EXPLOSION & 0.79 & 2.20 & $0.77-6.32$ \\
KOZLU*40-50*HAULAGE WORKER* METHANE EXPLOSION & 0.63 & 1.88 & $0.63-5.61$ \\
ARMUTCUK*30-40* PRODUCTION WORKER* METHANE EXPLOSION & 0.61 & 1.84 & $0.67-5.03$ \\
\hline
\end{tabular}

using mine (5), age group (3), occupation (4), and accident type (4). These relationships are illustrated in Table 2 and the associations and interactions are discussed thereafter.

Table 2 shows the main effects and higher-order interaction terms of the hierarchical loglinear model. The significance of the interaction terms was tested with the likelihood-ratio $\left(\chi^{2}\right.$ value) test $\left.{ }^{4}\right)$. It was found that the 3rd and 4th order interaction terms were not significant and the main effects and MINE*ACCIDENT, OCCUPATION*ACCIDENT, MINE*AGE and AGE* OCCUPATION interaction parameters are statistically significant $(p<0.05)$.

SPSS prints out the required parameters in the "Parameter Estimates" table of the output. One of these parameters is lambda and it is the usual designation for the effect coefficient. Lambdas appear as "coefficients" in the estimates column of this table. These parameters can be labeled as "b" coefficients and $\operatorname{Exp}(b)$ is the odds ratio (OR). The odds ratio is a type of effect size measure. Odds ratio of 1 indicate no effect. Although odds ratio greater than 1 indicate the variable in question increases the odds, odds less than 1 indicate the variable decreases the odds ${ }^{16)}$. If the odds ratio is greater than 1 and the lower bound of the confidence interval (CI) does not go below 1, it can be said that a proposed risk factor acts as a significant risk to accidents ${ }^{17)}$.

In this study, seeing that the fatal occupational accidents were evaluated, to achieve more detailed accident analyses, it was evaluated all of the probability from fourth-order interaction to main effect. The values obtained from SPSS package programme were used to calculate the odds ratios (OR) and their 95\% confidence intervals (CI). The most important results of the fourthorder interaction terms of the loglinear model are shown in Table 3.

According to the odds ratios given in Table 3, KOZLU*40-50*FIRING MAN*ROOF COLLAPSE has the highest odds ratio. This 4 th order interaction shows that the firing men in 40-50 yr old group were exposed to fatality accidents because of roof collapse. Some important issues taking attention in 4th order interactions can be given as KOZLU has the highest accident rate and the methane explosions are dangerous. When odds ratios and confidence intervals were evaluated together, an apparent 4th order interaction to conduce a fatal work accident could not be determined. After evaluation of 4th order interaction results, 3rd order interactions are evaluated and the values of important 
Table 4. The results of third-order interaction terms for the loglinear model

\begin{tabular}{|c|c|c|c|c|}
\hline INTERACTIONS & Effect Name & $\mathrm{b}$ & OR & $\mathrm{CI}$ \\
\hline \multirow{3}{*}{ MINE*OCCUPATION*ACCIDENT } & KOZLU* PRODUCTION WORKER* METHANE EXPLOSION & 0.75 & 2.12 & $1.07-4.18$ \\
\hline & ARMUTCUK* HAULAGE WORKER* METHANE EXPLOSION & 0.71 & 2.03 & $0.99-4.18$ \\
\hline & UZULMEZ* HAULAGE WORKER* TRANSPORTATION & 0.48 & 1.62 & $0.76-3.45$ \\
\hline \multirow{3}{*}{ MINE*AGE*OCCUPATION } & KOZLU*20-30* PRODUCTION WORKER & 0.35 & 1.42 & $0.75-2.68$ \\
\hline & KOZLU*40-50* FIRING MAN & 0.31 & 1.36 & $0.64-2.92$ \\
\hline & KOZLU*30-40*SUPPORTER & 0.29 & 1.34 & $0.70-2.56$ \\
\hline \multirow{3}{*}{ MINE*AGE*ACCIDENT } & KOZLU*40-50* METHANE EXPLOSION & 0.64 & 1.90 & $1.02-3.52$ \\
\hline & KOZLU*30-40* METHANE EXPLOSION & 0.59 & 1.80 & $1.00-3.26$ \\
\hline & KARADON*30-40*TRANSPORTATION & 0.41 & 1.51 & $0.79-2.87$ \\
\hline \multirow{3}{*}{ AGE*OCCUPATION*ACCIDENT } & 30-40* HAULAGE WORKER* TRANSPORTATION & 0.36 & 1.43 & $0.82-2.51$ \\
\hline & 40-50* HAULAGE WORKER* TRANSPORTATION & 0.35 & 1.42 & $0.79-2.53$ \\
\hline & 30-40* PRODUCTION WORKER* ROOF COLLAPSE & 0.31 & 1.36 & $0.82-2.27$ \\
\hline
\end{tabular}

3rd order interactions are given in Table 4.

The most important 3rd order interaction probabilities are given in Table 4. Firstly, MINE*OCCUPATION* ACCIDENT 3rd order interaction was evaluated and it was found that KOZLU*PRODUCTION WORKER* METHANE EXPLOSION interaction was the most important risk group. This interaction shows that the possibility of death related to methane explosion for the production workers in Kozlu is high. From MINE*AGE*OCCUPATION interaction, it was found that KOZLU*20-30*PRODUCTION WORKER interaction was the most important risk group. This interaction indicates that the possibility of being exposed to fatal work accidents for the 20-30 yr old group production workers in Kozlu is high. 40-50 yr old group in Kozlu was more likely to be affected by methane explosion according to the MINE*AGE*ACCIDENT 3rd order interaction. The probability of exposure to fatal work accidents related to transportation was found high for 30-40 yr old group transportation workers as seen from AGE*OCCUPATION*ACCIDENT interaction. When odds ratios and confidence intervals were evaluated together, it could be said that the possibility of 30-40 and 40-50 yr old group production workers being exposed to fatal work accidents because of methane explosion is very high. By evaluating the other remaining interactions in the same way, the reasons related to the accidents for mine, occupation or age group can be defined. After evaluation of 3rd order interactions, the 2 nd order interactions were evaluated and obtained important results are given in Table 5 .

When the 2nd order interactions given in Table 5 are evaluated, MINE*ACCIDENT interaction shows that Kozlu and Armutcuk are dangerous due to methane explosions and Uzulmez is dangerous due to roof collapses. OCCUPATION*ACCIDENT interaction shows that transportation workers have high possibility of exposure to fatal work accidents due to transportation and production workers and supporters have high possibility of exposure to fatal work accidents due to roof collapses. When MINE*AGE interaction is evaluated, it is found that workers at 30-40 yr old group in Kozlu have high accident risk. AGE*OCCUPATION interaction shows that production workers at 30-40 yr old group has the highest risk. MINE*OCCUPATION interaction shows that production workers in Kozlu and Karadon, and transportation workers in Armutcuk have high risk. When AGE*ACCIDENT 2nd order interaction is evaluated, it is found that workers at $30-40 \mathrm{yr}$ old group have high risk of fatal work accidents due to roof collapse and methane explosion. When the odds ratios and confidence intervals are evaluated together, it can be said that the methane explosions in Kozlu and Armutcuk have high risk, 30-40 yr old group production workers have high risk, and moreover transportation workers are exposed to fatal work accidents due to transportation and production workers are exposed to fatal work accidents due to roof collapse. After evaluation of 2 nd order interactions, the main effects are evaluated and the results are given in Table 6 .

When Table 6 is evaluated by taking into account both the odds ratios and confidence intervals, it can be said that Kozlu is the mine having the highest risk of fatal work accident. It is followed by Armutcuk and Karadon. It can be said that Uzulmez and Amasra have less occupational fatality risk. The age group having the highest risk of being exposed to accident is 30-40. Production workers are the job group having the highest risk being exposed to fatal work accident. Haulage workers and supporter nearly have similar risk; firing man has less accident risk. The most important factor in creating fatal work accident is the roof collapses. 
Table 5. The results of second-order interaction terms for the loglinear model

\begin{tabular}{llccc}
\hline \multicolumn{1}{c}{ INTERACTIONS } & \multicolumn{1}{c}{ Effect Name } & $\mathrm{b}$ & OR & CI \\
\hline \multirow{3}{*}{ MINE*ACCIDENT } & KOZLU* METHANE EXPLOSION & 0.90 & 2.46 & $1.66-3.65$ \\
& ARMUTCUK* METHANE EXPLOSION & 0.59 & 1.80 & $1.21-2.69$ \\
& UZULMEZ* ROOF COLLAPSE & 0.40 & 1.49 & $0.98-2.27$ \\
\hline \multirow{3}{*}{ OCCUPATION*ACCIDENT } & HAULAGE WORKER* TRANSPORTATION & 0.61 & 1.84 & $1.28-2.64$ \\
& PRODUCTION WORKER* ROOF COLLAPSE & 0.60 & 1.82 & $1.30-2.56$ \\
& SUPPORTER* ROOF COLLAPSE & 0.31 & 1.36 & $0.94-1.98$ \\
\hline \multirow{3}{*}{ MINE*AGE } & KOZLU*30-40 & 0.32 & 1.38 & $0.97-1.96$ \\
& ARMUTCUK*20-30 & 0.089 & 1.09 & $0.74-1.61$ \\
AGE*OCCUPATION & UZULMEZ*40-50 & 0.088 & 1.09 & $0.73-1.63$ \\
\hline & 30-40* PRODUCTION WORKER & 0.34 & 1.40 & $1.03-1.91$ \\
& 40-50* HAULAGE WORKER & 0.16 & 1.17 & $0.83-1.67$ \\
& 20-30* PRODUCTION WORKER & 0.12 & 1.13 & $0.81-1.56$ \\
\hline MINE*OCCUPATION & KOZLU*PRODUCTION WORKER & 0.26 & 1.30 & $0.87-1.93$ \\
& ARMUTCUK* HAULAGE WORKER & 0.20 & 1.22 & $0.79-1.89$ \\
& KARADON* PRODUCTION WORKER & 0.18 & 1.20 & $0.79-1.80$ \\
\hline AGE*ACCIDENT & 30-40* ROOF COLLAPSE & 0.31 & 1.36 & $0.99-1.87$ \\
& $40-50 *$ METHANE EXPLOSION & 0.15 & 1.16 & $0.82-1.64$ \\
& 30-40* METHANE EXPLOSION & 0.11 & 1.12 & $0.80-1.56$ \\
\hline
\end{tabular}

Table 6. The results of main effects for the loglinear model

\begin{tabular}{llccc}
\hline \multirow{2}{*}{ MAIN EFFECTS } & \multicolumn{1}{c}{ Effect Name } & $\mathrm{b}$ & OR & CI \\
\hline \multirow{4}{*}{ MINE } & KOZLU & 0.32 & 1.38 & $1.10-1.72$ \\
& ARMUTCUK & 0.11 & 1.12 & $0.89-1.40$ \\
& KARADON & 0.05 & 1.05 & $0.84-1.32$ \\
& UZULMEZ & -0.007 & 0.99 & $0.79-1.25$ \\
& AMASRA & -0.108 & 0.90 & $0.71-1.14$ \\
\hline \multirow{4}{*}{ AGE } & 30-40 & 0.33 & 1.39 & $1.17-1.65$ \\
& 40-50 & 0.02 & 1.02 & $0.85-1.22$ \\
& 20-30 & 0.01 & 1.01 & $0.85-1.21$ \\
\hline \multirow{5}{*}{ ACCUPATION } & PRODUCTION WORKER & 0.44 & 1.55 & $1.28-1.88$ \\
& HAULAGE WORKER & 0.08 & 1.08 & $0.88-1.33$ \\
& SUPPORTER & 0.004 & 1.00 & $0.82-1.24$ \\
& FIRING MAN & -0.16 & 0.85 & $0.69-1.06$ \\
\hline \multirow{4}{*}{ ACIDENT } & ROOF COLLAPSE & 0.30 & 1.35 & $1.11-1.64$ \\
& METHANE EXPLOSION & 0.18 & 1.20 & $0.98-1.47$ \\
& TRANSPORTATION & 0.11 & 1.12 & $0.91-1.37$ \\
& GAS POISONING & -0.22 & 0.80 & $0.65-0.99$ \\
\hline
\end{tabular}

The other accident reasons are methane explosions, transportation, and gas poisoning.

\section{Conclusions}

Preventing fatal occupational accidents or decreasing them is only possible by the analyses of the accident occurred in past and by taking precautions related to the results of these analyses. When the fatal accidents in the mines of Turkish Hardcoal Enterprises are evaluated by hierarchical loglinear analysis method, it is found out that the most risky job group is the production worker and this job group has high possibility of exposure to fatal work accidents due to roof collapse and methane explosion. The workers at the $30-40 \mathrm{yr}$ age group, especially production workers, are exposed to the most of the accidents. It can be said that transportation workers must be careful about the transportation equip- 
ments and the supporter must be carefully about roof collapse. When the important interactions in the analyses are evaluated, it is found out that production worker in Kozlu and Armutcuk have high probability of exposure to fatal work accidents because of methane explosion. According to these results, it will be effective to decrease the fatal work accidents by improving the supporting systems in underground mines. In order to reduce the methane explosions, it is required to remove the methane from the mines by drainage systems. In addition, respiratory protective equipment should be used to avoid the gas poisoning. Moreover, in the training related to work accidents, the occupational job groups must be taken into consideration and they must be educated for the possible risks. Because the important interactions can be attained by using hierarchical loglinear analysis method, important information can be obtained to reduce the fatal occupational accidents.

\section{Acknowledgements}

The authors thank to the management of Turkish Hardcoal Enterprises.

\section{References}

1) Ghosh AK, Bhattacherjee A, Chau N (2004) Relationships of working conditions and individual characteristics to occupational injuries: a case-control study in coal miners. J Occup Health 46, 470-8.

2) Kecojevic V, Komljenovic D, Groves W, Radomsky M (2007) An analysis of equipment-related fatal accidents in U.S. mining operations: 1995-2005. Saf Sci 45, 864-74.

3) Donoghue AM (2004) Occupational health hazards in mining: an overview. Occup Med 54, 283-9.

4) Maiti J, Bhattacherjee A, Bangdiwala SI (2001) Loglinear model for analysis of cross-tabulated coal mine injury data. Inj Control Saf Promot 8, 229-36.

5) Jeong BY (1999) Comparisons of variables between fatal and nonfatal accident in manufacturing industry. Int J Ind Ergon 23, 565-72.

6) Kucuker H (2006) Occupational fatalities among coal mine workers in Zonguldak, Turkey, 1994-2003. Occup Med 56, 144-6.

7) TurkStat (2007) Turkish Statistical Institute. http:// www.tuik.gov.tr/PreHaberBultenleri.do?id=3916. Accessed February 10, 2008.

8) Agresti A (2002) Categorical data analysis, 710, John Wiley \& Sons, New Jersey.

9) Jeansonne A (2008) Loglinear Models. http:// online.sfsu.edu/ efc/classes/biol710/loglinear/ Log\%20Linear\%20Models.pdf. Accessed November 16, 2008.

10) Berry KF (2007) The Effect of Missing Data in the Analysis of a Bariatric Surgery Program. http://dspace. nitle.org/bitstream/10090/4914/1/247.pdf. Accessed October 8, 2008.

11) Sari M, Duzgun HSB, Karpuz C, Selcuk AS (2004) Accident analysis of two Turkish underground coal mines. Saf Sci 42, 675-90.

12) Maiti J, Bhattacherjee A (1999) Evaluation of risk of occupational injuries among underground coal workers through multinominal logit analysis. J Safety Res 30, 93-101.

13) Jansen JC, Brent AC (2005) Reducing accidents in the mining industry-an integrated approach. J S Afr Inst Min Metall 105, 719-25.

14) Maiti J, Bhattacherjee A (2001) Predicting accident susceptibility: a logistic regression analysis of underground coal mine workers. J S Afr Inst Min Metall 101, 203-8.

15) Karacan CO, Okandan E (2000) Fracture/cleat analysis of coals from Zonguldak Basin (northwestern Turkey) relative to the potential of coalbed methane production. Int J Coal Geol 44, 109-25.

16) Garson GD (2008) Log-Linear, Logit, and Probit Models. http://faculty.chass.ncsu.edu/garson/PA765/ logit.htm. Accessed December 29, 2008.

17) Shephard N (2004) Calculating and Interpreting Odds-Ratios. http://slack.ser.man.ac.uk/theory/ association_odds.html. Accessed February 16, 2009. 